\title{
Defining of criteria for flue gas decarbonization efficiency in methanation reactors with membrane technology
}

\author{
Gheorghe Lăzăroiu ${ }^{1}$, Lucian Mihăescu ${ }^{2}$, Dana-Alexandra Ciupăgeanu ${ }^{1}{ }^{*}$, Rodica-Manuela Grigoriu $^{1}$, and \\ Dana-Andreya Bondrea $^{1}$ \\ ${ }^{1}$ Power Engineering Faculty, University Politehnica of Bucharest, Splaiul Independentei 313, 060042 Bucharest (Romania) \\ ${ }^{2}$ Mechanics and Mechatronics Faculty, University Politehnica of Bucharest, Splaiul Independentei 313, 060042 Bucharest \\ (Romania)
}

\begin{abstract}
The paper presents an investigation on the conditions for implementing a methanation membrane decarbonator coupled to an energy installation that generates flue gases. The retention of the carbon dioxide content in the flue gases and its conversion to methane is envisaged. For start, low thermal power installations, employing natural gas as main fuel supply, are considered. Internal combustion engines (also working with natural gas fuel) are taken into account for the testing of the carbon dioxide retention process. For this, a classification of the flue gas composition by fuel categories is initially carried out. The decarbonation efficiency is defined and clarifications are made withal regarding the connection between the decarbonation installation and the energy plant. The first practical achievements are also presented, resulting from a decarbonator with a volume of $940 \mathrm{~cm}^{3}$ (having the inner diameter of $12 \mathrm{~cm}$ and a height of 50 $\mathrm{cm}$ ). The results prove that the proposed solution has great potential for practical applications, further research being however necessary. In terms of operating costs (including hydrogen consumption), it is remarked that they can be reduced by exploiting the methane production and eliminating the carbon tax, extending the integration perspective form economic point of view.
\end{abstract}

\section{Introduction}

At first, carbon dioxide $\left(\mathrm{CO}_{2}\right)$ methanation processes targeted exclusively methane $\left(\mathrm{CH}_{4}\right)$ production, for chemical or energy uses. As the interest on the subject of $\mathrm{CO}_{2}$ conversion grew constantly, several methanation technologies have been developed, in addition to the chemical ones. In particular, gasification, plasma employment or even pyrolysis are investigated or used nowadays [1], [2].

Today, depollution requirements in reference to classical power plants highlight the need to reduce $\mathrm{CO}_{2}$ emissions from flue gases. In this context, new questions about integrating methanization technologies on the exhaust path of classical power plants arise [3]. The feasibility and efficiency of $\mathrm{CO}_{2}$ emissions reduction in the flue gases depends primarily on their composition. The thermal level of the flue gases plays an important role as well, corrections only in methanation reactors, for large amounts of flue gases involve high costs [4], [5]. Generally, the flue gases contain low amounts of $\mathrm{CO}_{2}$, the main components in the exhaust stream being represented by nitrogen $\left(\mathrm{N}_{2}\right)$ and water vapor $\left(\mathrm{H}_{2} \mathrm{O}\right)$. The amount of water vapors within the flue gas enable a reduction (up to full replacement) of the water vapor requirement in the methanation reactor, as displayed in Figure 1 [6]. Moreover, the composition of the flue gas depends on the nature of the fossil fuel used, if we accept the conclusion of the Kyoto Protocol, on the total zero or partially zero emission of biomass combustion [7].

A promising solution in order to reduce operational related costs is remarked in the possibility of producing hydrogen from renewable energy sources (RES) [8]. Solar energy and biomass are of in great interest, showing potential also for enabling the reaction conditions, supplying the energy for heating the reactants or cooling for water vapor condensation [9], [10].

In this paper, the level of costs is not addressed, the present research focusing on the possibility of technical application of the catalytic methanation technology to flue gases produced in the energy field. It is highlighted that the proposed research addresses exclusively the issues related to energy installations where adequate decarbonization facilities (in particular through methanation) must be coupled taking into account the flue gas characteristics, according to the prior fuel combustion.

\footnotetext{
${ }^{*}$ Corresponding author: dana ciupageanu@yahoo.com
} 
The second section presents the analysis of flue gases composition, including the equations serving to evaluate the emissions. Section 3 addresses the operation of a catalyst methanizer, while the following section introduces the decontamination of $\mathrm{CO}_{2}$ as $\mathrm{CH}_{4}$ production technology, with two-folded advantages. Conclusions are exposed in the last section.

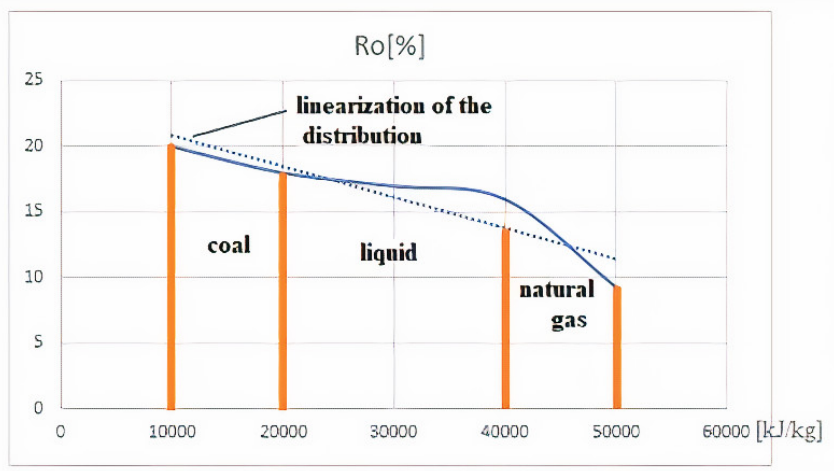

Fig. 1. Variation of $\mathrm{CO}_{2}$ participation in the flue gases $(\lambda=1)$.

\section{Flue gases composition analysis}

The emission of flue gases, including $\mathrm{CO}_{2}$, is determined based on the stoichiometry of the combustion reactions. Accurate calculations require basic knowledge of fuel analysis in order to evaluate the $\mathrm{CO}_{2}$ emission level [11]. In the case when only the lower calorific value $H_{i}^{i}$ is known (measured in $M J / k g$ for solid and liquid fuels in $M J / m_{N}^{3}$ for gaseous fuels) in the initial conditions characterizing the state of the fuel, empirical calculation relations can be employed, providing acceptable accurate results [12], [13]. Thus, depending on the lower calorific value, the equations presented forward allow assessing the $\mathrm{CO}_{2}$ emission in the flue gas flow, taking into account as input only the lower calorific value of the fuel [14].

- $\quad$ Emission of $\mathrm{CO}_{2}$ :

Solid fuels, $V_{\mathrm{CO}_{2}}=0,101619+0,043991 H_{i}^{i}\left[\mathrm{~m}_{N}^{3} / \mathrm{kg}\right]$

Liquid fuels, $V_{\mathrm{CO}_{2}}=1,26601+0,0075569 H_{i}^{i}\left[m_{N}^{3} / \mathrm{kg}\right]$

Gaseous fuels, $V_{\mathrm{CO}_{2}}=-0,142711+0,0325796 H_{i}^{a n} \quad\left[m_{N}^{3} / m_{N}^{3}\right]$

- $\quad$ Stoichiometric flue gas emission $(\lambda=1)$ :

Solid fuels, $V_{g}^{o}=1,57933+0,217974 H_{i}^{i}\left[m_{N}^{3} / k g\right]$

Liquid fuels, $V_{g}^{o}=-0,728139+0,292333 H_{i}^{i}\left[m_{N}^{3} / k g\right]$

Gaseous fuels, $V_{g}^{o}=0,618368+0,277279 H_{i}^{a n} \quad\left[m_{N}^{3} / m_{N}^{3}\right]$

The presence of excess air $(\lambda>1)$, increases the actual flue gas content, $V_{g}$, calculable with eq. (3):

$V_{g} \approx V_{g}^{o}+(\lambda-1) V_{\text {aum }}^{o} \quad\left[m_{N}^{3} / k g\right] ;\left[m_{N}^{3} / m_{N}^{3}\right]$

where, $V_{\text {aum }}^{o}$ is the amount of stoichiometric air for burning the unit of fuel. (4b):

The participation of $\mathrm{CO}_{2}$ in the flue gas is defined by the ratio $R_{\mathrm{CO}_{2}}$ is evaluated according to eq. (4a) and

$$
R_{\mathrm{CO}_{2}}^{o}=\frac{V_{\mathrm{CO}_{2}}}{V_{g}^{o}}, \text { for stoichiometric combustion }
$$




$$
R_{\mathrm{CO}_{2}}=\frac{V_{\mathrm{CO}_{2}}}{V_{g}}, \text { for burning with excess air }
$$

According to Figure 1, the participation of $\mathrm{CO}_{2}$ in the flue gases (excess air $\lambda=1$ ) decreases with increasing calorific value. According to the equations previously presented, the participation of $\mathrm{CO}_{2}$ in the flue gas is calculated for different values of the lower calorific power, the results being listed in Table 1 .

Table 1. Stoichiometric participation of $\mathrm{CO} 2$ in the flue gases.

\begin{tabular}{|c|c|}
\hline $\mathbf{R}_{\mathbf{o}}[\mathbf{\%}]$ & $\mathbf{H}_{\mathbf{i}}^{\mathbf{i}}[\mathbf{k J} / \mathbf{k g}]$ \\
\hline 20 & 10000 \\
\hline 18 & 20000 \\
\hline 17 & 30000 \\
\hline 16 & 40000 \\
\hline 9.3 & 50000 \\
\hline
\end{tabular}

It is mentioned that the calorific value of natural gas is considered equal to $53190 \mathrm{k} \mathrm{J} / \mathrm{kg}$, resulting a stoichiometric $\mathrm{CO}_{2}$ participation in the flue gases of $R_{o}=9.34 \%$. Moreover, it is highlighted that gaseous fuels show the lowest value for $\mathrm{CO}_{2}$ participation in the flue gases.

To exploit the potential in the flue gas flow and reduce the $\mathrm{CO}_{2}$ emissions level, a decontamination solution is proposed. Specifically, the layout of a depollution methanizer is shown in Figure 2. It is not mandatory that the entire amount of flue gas is taken over by the methanizer, the difference being discharged through the chimney of the installation (this is the case of high power energy installations).

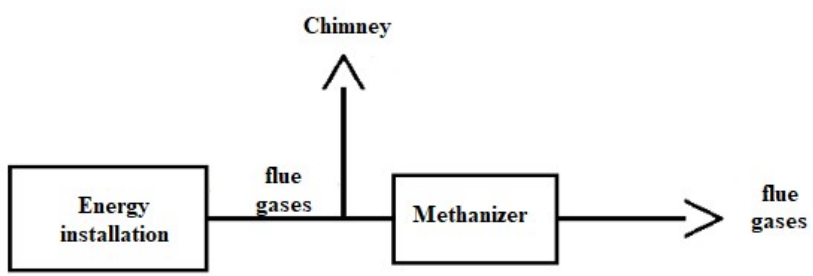

Fig. 2. $\mathrm{CO}_{2}$ decontamination facility based on methanation.

\section{Operation of a catalyst methanizer}

There is a lot of effort currently investigating $\mathrm{CH}_{4}$ production from $\mathrm{CO}_{2}$ and $\mathrm{H}_{2}$, by means of catalytic technology, as a solution with high practical potential among many methanation approaches [15], [16]. The efficiency of the catalytic methanation depends on the pressure and temperature in the reactor. The efficiency increases with pressure and temperature. The recommended temperature level in the reactor is $150-550^{\circ} \mathrm{C}$, the pressure being usually limited to 30 bar [17]. In these conditions, the reaction environment also contains water vapors. The catalytic methanation installation is schematically presented in Figure 3.

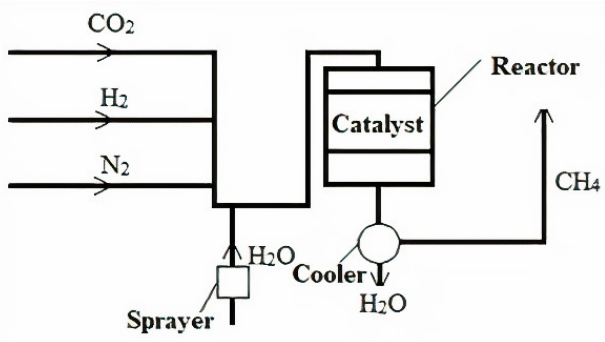

Fig. 3. Catalytic methanation scheme for $\mathrm{CO}_{2}$ 
The methanation reaction unfolds at temperature within the range of $150-550{ }^{\circ} \mathrm{C}$, following eq. (5):

$\mathrm{CO}_{2}+4 \mathrm{H}_{2} \rightarrow \mathrm{CH}_{4}+2 \mathrm{H}_{2} \mathrm{O}-165 \mathrm{~kJ} / \mathrm{mol}$

As practical implementation, at the National Research - Development Institute for Electrochemistry and Condensed Matter Timisoara (INCEMC Timisoara) a reactor with Ni Raney catalyst is developed. The reactor consists of a cylinder with a diameter of $120 \mathrm{~mm}$ and a height of $500 \mathrm{~mm}$. The maximum working temperature is between 200 and $300{ }^{\circ} \mathrm{C}$, depending on the sealing gasket used.

The material balance shows that the methanation for $1 \mathrm{~m}_{N}^{3}$ of $\mathrm{CO}_{2}$ results in $1 \mathrm{~m}_{N}^{3}$ of $\mathrm{CH}_{4}$ and $2 \mathrm{~m}_{N}^{3}$ of water vapors. As water vapors are captured and removed as condensation, the resulting volume of $\mathrm{CH}_{4}$ is equal to that of $\mathrm{CO}_{2}$. The stoichiometric reaction assumes a yield of $100 \%$. For sub-unitary yields, as in real cases, the equivalence of the transformation is given by eq. (6):

$\mathrm{CO}_{4}=0,01 \eta \mathrm{CH}_{2}$

For the Ni Raney catalyst the methanation reactions comprise two steps, according to eqs. (7a) and (7b):

$$
\begin{aligned}
& \mathrm{CO}_{2}+\mathrm{H}_{2} \rightarrow \mathrm{CO}+\mathrm{H}_{2} \mathrm{O} \\
& \mathrm{CO}_{2}+4 \mathrm{H}_{2} \rightarrow \mathrm{CH}_{4}+\mathrm{H}_{2} \mathrm{O}
\end{aligned}
$$

$\mathrm{H}_{2}$ consumption is similar to the global eq. (1), as well as the resulting amount of water.

\section{$4 \mathrm{CO}_{2}$ decontamination solution for $\mathrm{CH}_{4}$ combustion in energy installations}

The depollution efficiency is achieved for a combustion plant marked with $I A_{l}$, which hypothetically burns $1 m_{N}^{3} \mathrm{CH}_{4}$. The flue gas balance, after the coupling of a membrane methanizer is shown in Figure 4, considering the stoichiometric combustion process $(\lambda=1)$.

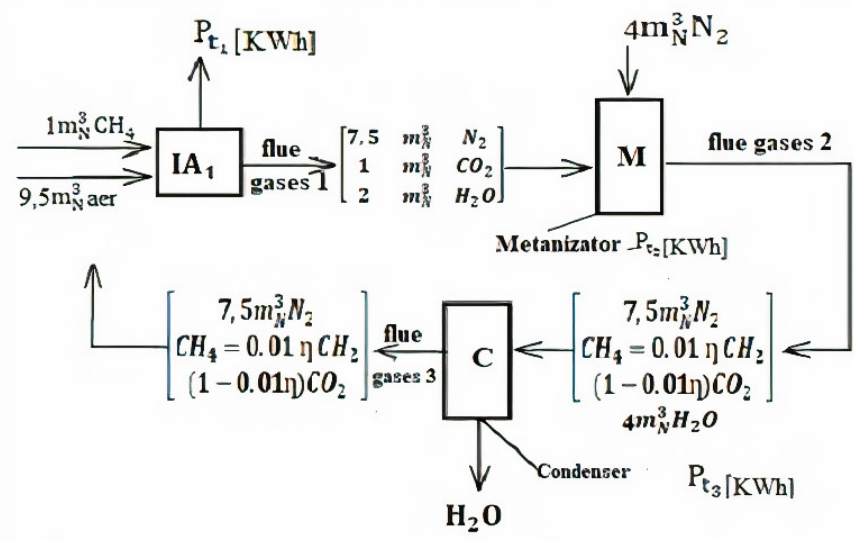

Fig. 4. Flue gas balance for combustion of $1 \mathrm{~m}_{\mathrm{N}}^{3} \mathrm{CH}_{4}$

It must be highlighted that, for $\mathrm{CH}_{4}$ combustion, considering the stoichiometric process does not introduce a significant deviation from reality, given that the excess air is very low anyway for such fuels $(\lambda=1.02-1.03)$.

The yield $\eta$, in $\%$, for the methanizer also taken into account. If the energy produced exclusively through combustion in the plant is $P_{t_{1}}$, the operation of the methanizer involves an energy consumption of $\left(-P_{t_{2}}\right)$. If operation with $\mathrm{CO}_{2}$ retention is considered, a condenser for water vapor needs to be inserted, a capacitor that will produce the energy $P_{t_{3}}$.

The flue gas balance indicates the presence of $\mathrm{CH}_{4}$ at the output of the installation, which is a much more harmful gas than $\mathrm{CO}_{2}$ if released the atmosphere. As a result, the combustion of flue gases 3 is taken into account in a new energy installation marked with $I A_{2}$. Figure 5 shows the proposed cascade energy production facility.

Further analysis are performed considering a methanizer efficiency of $90 \%(\eta=90 \%)$. 


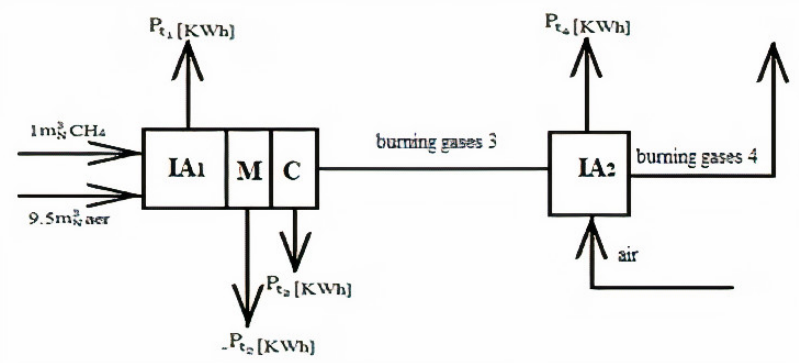

Fig. 5. Cascade combustion plant layout

The combustion plant $I A_{2}$, will produce the energy $P_{t_{4}}$, consuming the amount of air resulting from the stoichiometric calculation. The composition of the exhaust gases 3 , for $\eta=90 \%$, in stoichiometric conditions results as:

$$
\left[\begin{array}{ccc}
7,5 & m_{N}^{3} & N_{2} \\
0,9 & m_{N}^{3} & C_{4} \\
0,1 & m_{N}^{3} & C_{2}
\end{array}\right]=8,5 m_{N}^{3} \text { flue gases } 3
$$

As a percentage, the flue gases 3 , have the composition:

$$
\mathrm{CH}_{4}=10,6 \%, \mathrm{CO}_{2}=1,17 \%, \mathrm{~N}_{2}=88,23 \% \text {. }
$$

For this composition the calorific value of the flue gas is equal to $H_{i 3}^{i}=3800 \mathrm{~kJ} / \mathrm{m}_{N}^{3}$.

After combustion, the volume and composition of the flue gases discharged from $I A_{2}$ into the atmosphere shall be:

$$
\left[\begin{array}{ccc}
8,29 & m_{N}^{3} & N_{2} \\
0,21 & m_{N}^{3} & H_{2} O \\
0,18 & m_{N}^{3} & \mathrm{CO}_{2}
\end{array}\right]=8,68 m_{N}^{3}
$$

There is a decrease in $\mathrm{CO}_{2}$ concentration, from $R_{o}=9.34 \%$ at the exit of $I A_{1}$ to the value of $2.07 \%$ at the exit of $I A_{2}$.

The ratio to the power (energy) produced by combustion leads to the values:

$$
\begin{aligned}
& \text {-after } I A_{1} \text { for the combustion of } 1 m_{N}^{3} \mathrm{CH}_{4} \text {, it results: } \\
& E_{\mathrm{CO}_{2_{1}}}=\frac{V_{C O_{2_{1}}}}{P_{t_{1}}}=\frac{m_{C O_{2_{1}}}}{P_{t_{1}}}
\end{aligned}
$$

where $m_{\mathrm{CO}_{2}}$ is the mass amount of $\mathrm{CO}_{2}$ emitted in $\mathrm{g} \mathrm{CO}_{2}$.

Numerically:

$$
\begin{aligned}
E_{\mathrm{CO}_{21}} \approx & \frac{2000 \mathrm{~g}}{9,94 \mathrm{KWh}} \approx 200 \mathrm{~g} / \mathrm{kWh} \\
& \text {-after } I A_{2}, \text { the } \mathrm{CO}_{2} \text { emission will be: } \\
& E_{\mathrm{CO}_{2_{1}}} \approx \frac{0,18 m_{N}^{3} \mathrm{CO}_{2}}{P_{t_{1}}+P_{t_{2}}+P_{t_{3}}+P_{t_{4}}}\left[\frac{m_{N}^{3} \mathrm{CO}_{2}}{k W h}\right]
\end{aligned}
$$

if it is assumed that $P_{t_{2}}+P_{t_{3}} \approx 0$, the $\mathrm{CO}_{2}$ emission becomes:

$$
E_{\mathrm{CO}_{2_{1}}} \approx \frac{0,18 \mathrm{~m}_{N}^{3} \mathrm{CO}_{2}}{P_{t_{1}}+P_{t_{4}}}=\frac{360 \mathrm{~g}}{(9,94+1,05) k W}=32,75\left[\frac{\mathrm{g}}{\mathrm{kWh}}\right]
$$

There is a significant reduction in $\mathrm{CO}_{2}$ emissions from cascade combustion, the reduction being of about 6 times. 


\section{Conclusions}

The paper addressed some issues that need to be considered when using methanizers as a solution for decarbonating flue gases. To this aim, starting from the composition of the flue gases discharged by an energy installation, the analysis is performed taking into account natural gas fuel $\left(\mathrm{CH}_{4}\right)$. The calculations are performed for stoichiometric combustion $(\lambda=1)$, a situation very close to the real combustion conditions for gaseous fuels.

It is remarked that higher efficiencies for the methanizer are necessary, so that the $\mathrm{CH}_{4}$ content in the flue gas flow after the methanizer is enough for a general combustion in the second stage. For an efficiency of $90 \%$ in the methanation process, the volume evacuated at the output of the methanizer is characterized by a lower calorific value. For the model introduced in this paper, there is noticeable a significant reduction of the $\mathrm{CO}_{2}$ emissions after the second stage of combustion. Thus, this technology can be successfully applied to natural gas combustion.

As first applications, natural gas engine installation show increased potential, as the second combustion stage can be achieved in a simple way for the production of thermal energy. Regarding the application of the proposed technology to other fuels, it is highlighted that it must be treated selectively, representing a future research perspective. The present work is inceptive in the field of flue gas methanation, the calculations presented here being made for theoretical stoichiometric combustion of different fuels. Further research developed by the Authors aims investigating the excess air problem for all fuel types.

This work was supported by a grant of the Romanian Ministry of Research and Innovation, CCCDI-UEFISCDI, project number PN-III-P2-2.1-PED- 2019-2350, within PNCDI III (contract number 322PED/2020) and project number PN-III-P11.2-PCCDI-2017-0404/31PCCD/2018, within PNCDI.

\section{References}

1. I. Balcu et al., "Decarbonization of Low Power Applications through Methanation Facilities Integration,” 2019 IEEE PES Innov. Smart Grid Technol. Eur., pp. 1-5, Sep. 2019.

2. W. Wang and J. Gong, "Methanation of carbon dioxide: An overview," Front. Chem. Eng. China, vol. 5, no. 1, pp. 2-10, 2011.

3. H. Blanco, W. Nijs, J. Ruf, and A. Faaij, "Potential of Power-to-Methane in the EU energy transition to a low carbon system using cost optimization,” Appl. Energy, vol. 232, no. July, pp. 323-340, 2018.

4. International Renewable Energy Agency, "International Renewable Energy Agency: Renewable Energie: A Key Climate Soluation,” 2017.

5. M. da Graça Carvalho, M. Bonifacio, and P. Dechamps, "Building a low carbon society," Energy, 2011.

6. L. Mihaescu, T. Prisecaru, and I. Oprea, Cazane si turbine. Bucharest: Politehnica Press, 2002.

7. G. Lazaroiu, Holistica impactului surselor regenerabile de energie asupra mediului si climei. Vol. 2 Biomasa solida sursa de energie curata. Bucharest: Politehnica Press, 2018.

8. B. Castellani et al., "Thermal integration of a high-temperature co-electrolyzer and experimental methanator for Power-to-Gas energy storage system," Energy Convers. Manag., vol. 171, no. 4, pp. 140-155, Apr. 2018.

9. F. Salomone, E. Giglio, D. Ferrero, M. Santarelli, R. Pirone, and S. Bensaid, "Techno-economic modelling of a Power-to-Gas system based on SOEC electrolysis and CO2 methanation in a RES-based electric grid," Chem. Eng. J., no. xxxx, pp. 1-20, 2018.

10. M. Ancona et al., "Renewable energy storage system based on a Power-to-gas conversion process," Energy Procedia, vol. 101, 2016.

11. L. Mihaescu, Cazane de abur si apa fierbinte. Bucharest: PERFECT, 2007.

12. [12] G. Lazaroiu et al., "Experimental Investigations of Innovative Biomass Energy Harnessing Solutions," Energies, vol. 11, no. 12, p. 3469, 2018.

13. M. Prisecaru, Constructia si exploatarea cazanelor de abur si apa fierbinte. Bucharest: Politehnica Press, 2009.

14. G. Lazaroiu, Holistica impactului surselor regenerabile de energie asupra mediului si climei. Vol. 3 Spre o energetica circulara. Bucharest: Politehnica Press, 2020.

15. F. Meylan, F. Piquet, and S. Erkman, "Power-to-gas trough CO2 methanation: Assessment of the carbon balance regarding in directives," J. Energy Storage, vol. 11, 2007.

16. M. Thema, F. Bauer, and M. Sterner, "Power-to-gas: Electrolysis and methanation status review," Renew. Sustain. Energy Rev., vol. 112, 2019.

17. G. Emanuele, A. Lauzini, M. Santarelli, and P. Leone, "Synthetic natural gaz via integrated hightemperature electrolysis and methanation: Part I - Economic performance,” J. Energy Storage, vol. 1, 2015 . 